\title{
INVESTIGATION OF ALKALINE PHOSPHATASE EXPRESSION IN THE SMALL INTESTINES OF THE BRONZE TURKEY (MELEAGRIS GALLOPAVO)
}

\author{
D. Yovchev", G. Penchev \\ Department of Veterinary Anatomy, Histology and Embryology, Faculty of Veterinary \\ Medicine, Trakia University, Stara Zagora, Bulgaria
}

\begin{abstract}
The aim of our investigation was to study the expression of the enzyme Alkaline phosphatase in the small intestines of the bronze turkey in the age aspect. Forty clinically healthy bronze turkeys (twenty males and twenty females) were studied. The groups of the birds were at age 1, 7, 14, 28, 35, 49, 56, 90, 120 , and 240 days. Each group consisted of five males and five female birds. The enzyme's expression was investigated by Gomori staining. The most significant expression of tissue alkaline phosphatase was observed in the epithelial cells of the duodenum. It was weaker in the jejunum and weakest in the ileum. In the three intestinal segments, high enzyme activity was observed during the first weeks of hatching (from the $1^{\text {st }}$ to the $14^{\text {th }}$ day in the duodenum and ileum, and from the $1^{\text {st }}$ to the $28^{\text {th }}$ day in the jejunum).
\end{abstract}

Key words: bronze turkey, alkaline phosphatase, small intestines, histochemistry

\section{INTRODUCTION}

Intestinal alkaline phosphatase (AF) plays a protective role for the organism against intestinal inflammation, which is a concomitant pathognomonic symptom in a number of diseases. The therapeutic effect of this enzyme in the treatment of diseases affecting the middle and caudal parts of the digestive system in mammals has been proven $(1,2)$.

The epithelial cells in the small intestine in birds and mammals show a positive reaction to $\mathrm{AF}$. The highest expression of the enzyme is in the duodenum, and its activity is highest in the ileum. The intestinal mucosal layer and microvilli of enterocytes are characterized by high AF activity (2-4).

$\mathrm{AF}$ in the small intestine in broiler chickens is synthesized in the enterocytes of the intestinal villi and is localized in the apical membranes

\footnotetext{
*Correspondence to: David Yovchev, Department of Veterinary Anatomy, Histology and Embryology, Faculty of Veterinary Medicine, Trakia University, Stara Zagora, Bulgaria; e-mail: vetjovchev@yahoo.com
}

of the intestinal epithelial cells during their differentiation (5).

The importance of the study of AF in the small intestine of the broiler chickens is related to the biological role that the intestinal isoform of the enzyme plays in the inactivation of lipopolysaccharide endotoxins, which are major components of gram-negative bacteria. $\mathrm{AF}$ activity is a determining factor for the maturation of intestinal epithelial cells and for the metabolism of long-chain fatty acids and cholesterol (6).

Intestinal $\mathrm{AF}$ in the duodenum, jejunum and ileum in broiler chickens is a marker for the diagnosis of parasitological diseases such as Eimeriosis (7).

The activity and enzymatic expression of intestinal AF increased in the small intestine in broiler chickens in the post-hatching period. In the epithelial cells of the intestinal villi and crypts of the duodenum, jejunum and ileum, a strong reaction of the studied enzyme is observed (8).

In erosion of the intestinal mucosa caused by improper diet in growing turkeys, $\mathrm{AF}$ 
stimulates the secretory processes from the villous surface of the small intestine. Increased activity and expression of $\mathrm{AF}$ in small intestinal enterocytes is a marker of impaired intestinal mucosal integrity (9).

The activity and expression of AF in the smallintestine in broiler chickens in the posthatching period is affected depending on the $\operatorname{diet}(10)$.

Studies on the enzymatic activity of AF in the small intestine in broiler chickens show that it reaches peak levels on the second day after hatching. During embryonic development, its activity begins to manifest slowly from the ninth to the eighteenth day, and before this period, it is completely absent $(11,12)$.

The activity of alkaline phosphatase in the duodenum, jejunum and ileum in broiler chickens increases significantly from the first to the fourteenth day. After this period until the thirty-fifth day, the activity of the enzyme decreases and remains constant until the fiftysixth day in the three segments of the small intestine. The enzyme activity increases most significantly in the duodenum from the first to the fourteenth day, less in the jejunum and least in the ileum (6).

AF activity and expression in the small intestine in broiler chickens is reduced in severe necrotic lesions of the intestinal mucosa (13).

Due to the lack of literature data on the expression and activity of intestinal AF in the small intestine in the bronze turkey in the age aspect, we conducted the enzymohistochemical study. The obtained results could be used as an innovative basis for monitoring the homeostasis in the small intestine in the research species, the applied diet and the prevention of diseases of the digestive system.

\section{MATERIALS AND METHODS}

Forty clinically healthy bronze turkeys (twenty males and twenty females) were studied. The groups of the birds were at age 1, 7, 14, 28, 35 and 49 days. Each group consisted of five males and five female birds. The enzyme's expression was investigated by Gomori staining. Eighteen tissue samples (three from the middle of each segment of the small intestine) from the respective age group were used to determine the expression of alkaline phosphatase in the small intestine. Histological specimens were fixed in $90 \%$ alcohol for 24 hours at $22{ }^{\circ} \mathrm{C}$. The sections were transferred to $96 \%$ alcohol for one hour, then placed twice in absolute alcohol for 15 minutes and transferred to xylene twice for 30 minutes. Histological sections were embedded in paraffin. This was followed by cooling, cutting, and gluing on the slide. The resulting preparations were dewaxed in xylene and then placed successively in absolute alcohol, $40 \%$ acetone, and water. The preparations were transferred to an incubation medium and placed in a thermostat at $37^{\circ} \mathrm{C}$ for 2 hours. They were sequentially placed in $40 \%$ acetone, then transferred to $20 \%$ cobalt nitrate solution for $5 \mathrm{~min}$, in $40 \%$ acetone for $3 \mathrm{~min}$ and washed in pure acetone. This was followed by dehydration in alcohol, clarification in xylene and inclusion in entelan. Black deposits of cobalt nitrate showed the presence of enzyme activity $(14,15)$.

The obtained preparations were observed with a light microscope - Leica DM 1000, and the results were documented using a digital camera Leica DPC 290. The obtained data were processed using software LAS V 410.0 2016.

The study was conducted in the Department of Cytology, Histology and Embryology and the Department of Animal Anatomy in the Department of Veterinary Anatomy, Histology and Embryology, at the Faculty of Veterinary Medicine of the Thracian University, Stara Zagora.

\section{RESULTS}

The expression of $\mathrm{AF}$ in the duodenum in the bronze turkey increased from the first to the fourteenth day. It was most significant and uniformly manifested in the apical part of the epithelial cells covering the villi intestinales and intestinal crypts. After this period until day thirty-five, the epithelial cells showed decreasing AF activity, remaining constant until day two hundred and forty (Figures 1 and 2 and Table 1 ).

Enzyme histochemical examination of the jejunum in the bronze turkey showed that the most significant expression of tissue AF was observed in the apical part of epithelial cells covering the intestinal villi, in the period from the first to the twenty-eighth day. This expression was weaker than that reported in the duodenum. In the following age groups, the enzyme activity decreased and remained almost constant until day two hundred and forty (Figures 3 and 4 and Table 1). 


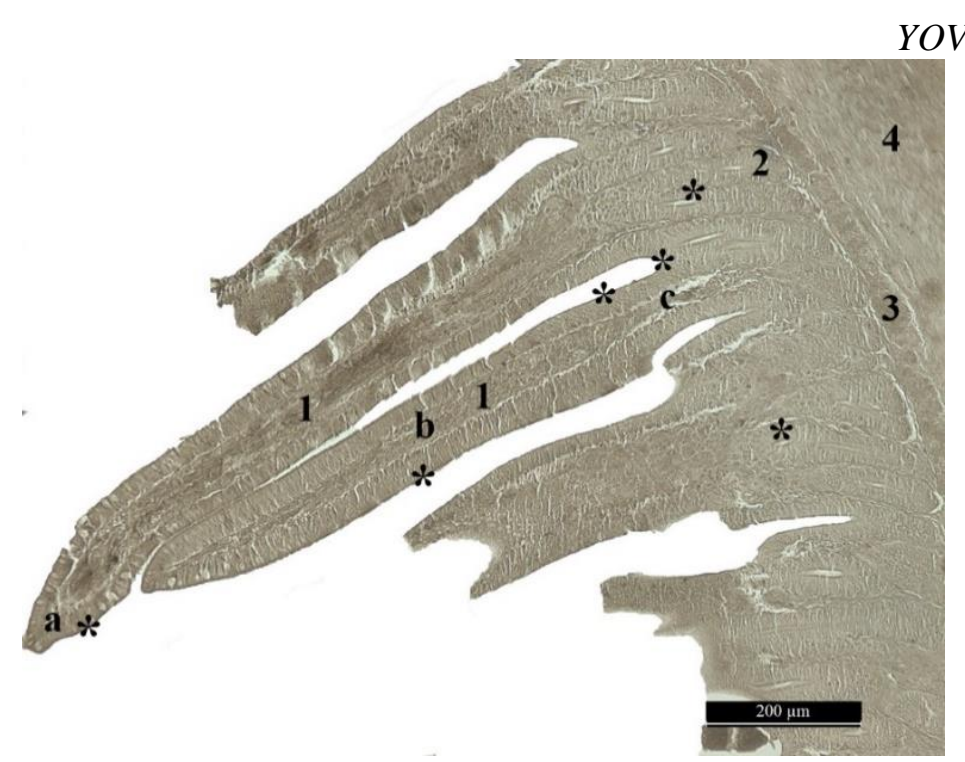

Figure 1. Expression of tissue AF in the duodenum in a bronze turkey (age - 7 days). (*) AF expression; (1) intestinal villi; (a) tip of the intestinal villi; (b) middle part of the intestinal villi; (c) base of the intestinal villi; (2) gll. intestinales; (3) lamina muscularis mucosae; (4) tunica muscularis. by Gomori. Line $=200 \mu \mathrm{m}$.

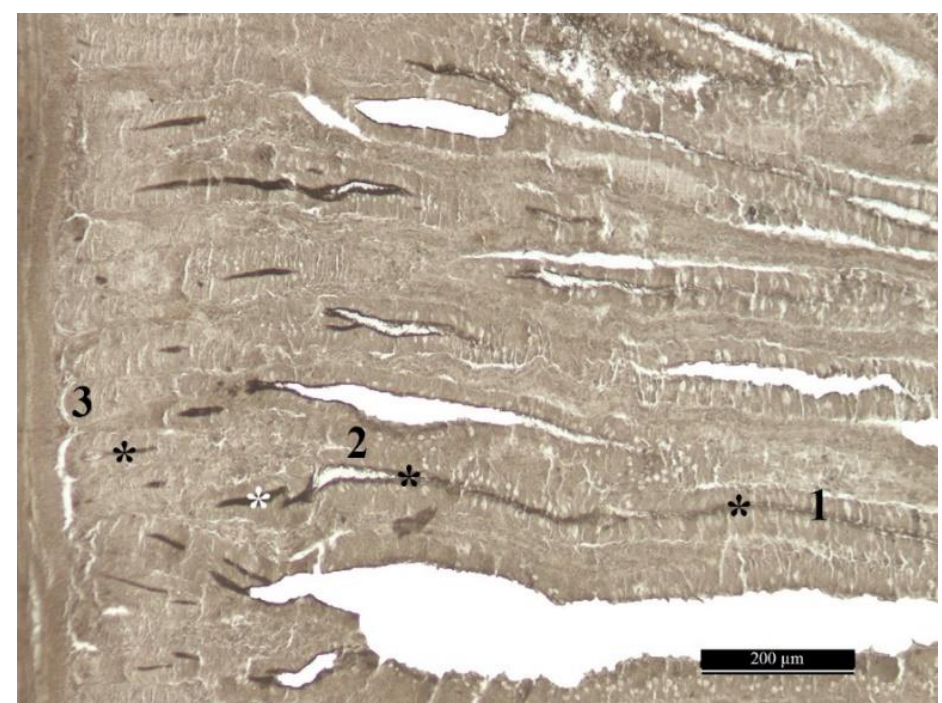

Figure 2. Expression of tissue AF in the duodenum in a bronze turkey (age - 120 days). (*) AF expression; (1) middle part of the intestinal villi; (2) base of the intestinal villi; (3) gll. intestinales. by Gomori. Line $=200 \mu \mathrm{m}$.

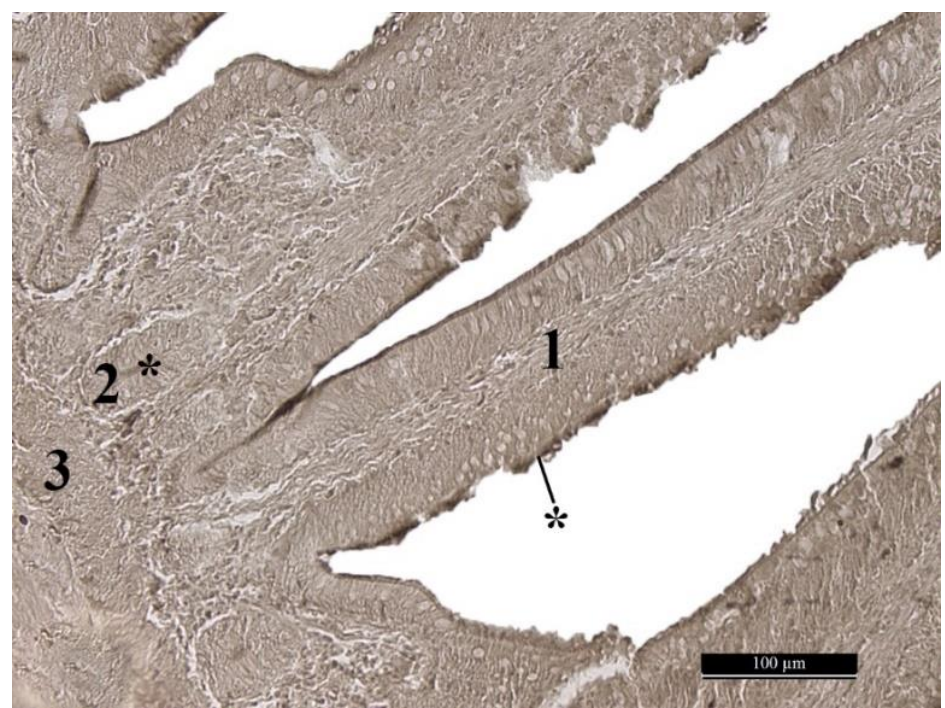

Figure 3. Expression of tissue AF in the jejunum of the bronze turkey (age- 14 days). (*) AF expression; (1) intestinal villi; (2) gll. intestinales; (3) lamina muscularis mucosae. by Gomori. Line $=100 \mu \mathrm{m}$. 
YOVCHEV D., et al.

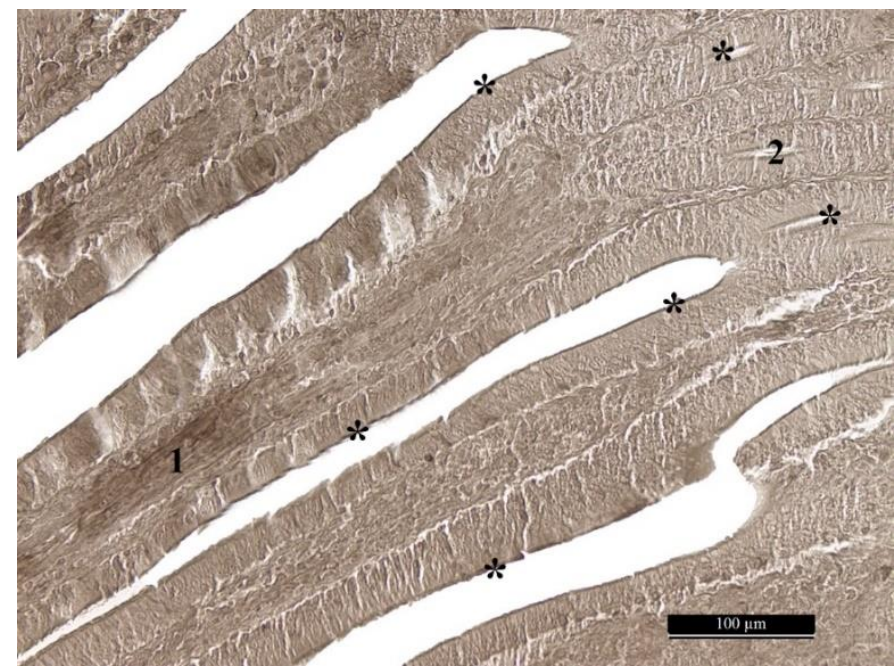

Figure 4. Expression of tissue AF in the jejunum of the bronze turkey (age-49 days). (*) AF expression; (1) intestinal villi; (2) gll. intestinales. by Gomori. Line $=100 \mu \mathrm{m}$.

The expression of tissue AF in the ileum in the bronze turkey was the most significant and increased similarly to that seen in the duodenum and jejunum in the first age periods (from the first to the fourteenth day). The enzyme activity was significantly lower than that observed in the duodenum and jejunum (Figures 5 and 6 and Table 1).

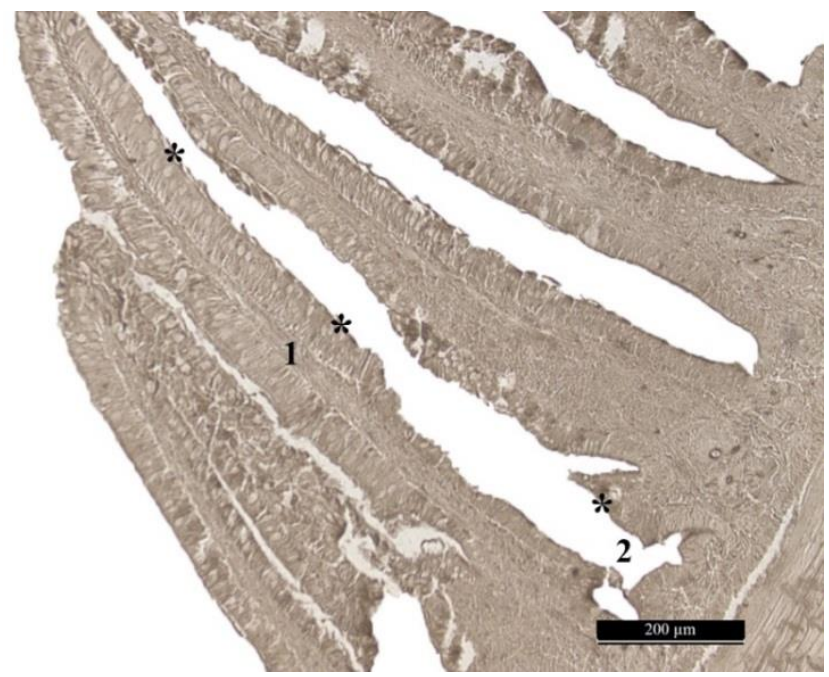

Figure 5. Expression of tissue AF in the ileum in the bronze turkey (age - 14 days). (*) AF expression; (1) intestinal villi; (2) intestinal crypt. by Gomori. Line $=200 \mu \mathrm{m}$.

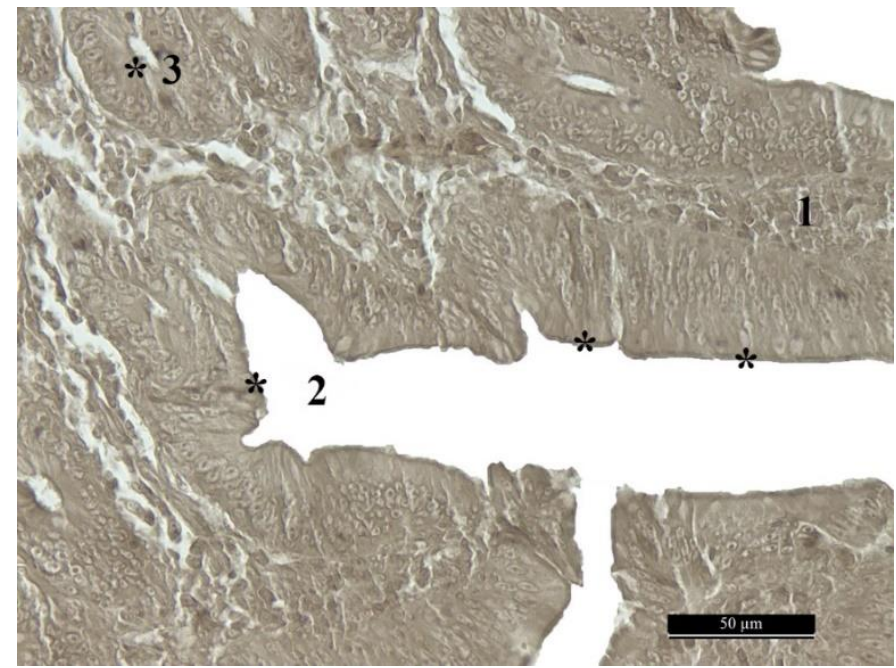

Figure 6. Expression of tissue AF in the ileum in the bronze turkey (age - 56 days). (*) AF expression; (1) intestinal villi; (2) intestinal crypt. by Gomori. Line $=50 \mu \mathrm{m}$. 
YOVCHEV D., et al.

Table 1. AF activity in the duodenum, jejunum and ileum in the bronze turkey (age - from the first day to 240 days), in accordance to the intensity of the enzyme reaction.

\begin{tabular}{|c|c|c|c|c|c|c|c|c|c|c|}
\hline \multirow[t]{2}{*}{ organ } & \multicolumn{10}{|c|}{ A GE (d a y s ) } \\
\hline & 1 & 7 & 14 & 28 & 35 & 49 & 56 & 90 & 120 & 240 \\
\hline duodenum & ++ & ++ & $+++(+)$ & +++ & +++ & +++ & +++ & +++ & +++ & +++ \\
\hline jejunum & ++ & ++ & $+++(+)$ & $+++(+)$ & +++ & +++ & +++ & +++ & +++ & +++ \\
\hline ileum & + & ++ & $+++(+)$ & +++ & +++ & +++ & +++ & +++ & +++ & +++ \\
\hline
\end{tabular}

* Intensity of the enzymatic reaction: "+" medium in degree, "++" positive, "+++" strong, "+++ (+)" very strong.

\section{DISCUSSION}

The expression of AF in the small intestine of the bronze turkey found by us gives a high morphological value to the obtained results. The activity and localization of this isoenzyme can be used as markers in the study of the status of the intestinal mucosa and in the diagnosis of intestinal diseases specific to these birds. Therefore, these data complement the known biological significance of tissue AF in the middle and caudal divisions of the mammalian system $(1,2)$.

According to our results, the epithelial cells in the duodenum, jejunum and ileum in the bronze turkey show a positive reaction to AF. It should be noted that the highest expression of the enzyme is in the duodenum, in all age groups. These results confirm the findings on the expression of $\mathrm{AF}$ in the small intestine in birds and mammals (2-4).

Our results regarding the localization of intestinal AF in the apical parts of enterocytes complement the studies for the expression of this enzyme in the small intestine in broiler chickens (5).

Our data on the expression and activity of intestinal $\mathrm{AF}$ can be used as a marker to determine the normal development of enterocytes in different age groups. This theory complements the facts (6) on the relationship between $\mathrm{AF}$ expression in the small intestine and changes in epithelial cells in broilers.

Based on data (7) for the importance of $\mathrm{AF}$ in the small intestine in broiler chickens, we can assume that this isoenzyme is an important marker in the diagnosis of specific parasitosis in bronze turkey, including Eimeriosis.

We assume that the activity and expression of intestinal AF increase in the small intestine of the bronze turkey in the period after hatching. It is important to note that we found strong expression of the enzyme in the epithelial cells of the intestinal villi and crypts of the duodenum, jejunum and ileum in the first age groups (from the $1^{\text {st }}$ to the $14^{\text {th }}$ day in the duodenum and ileum and from $1^{\text {st }}$ until the $28^{\text {th }}$ day in the jejunum). Therefore, our data correspond to that is known previously, regarding the expression of $\mathrm{AF}$ in the small intestine in broiler chickens (8).

We conclude that the expression of $\mathrm{AF}$ in the small intestine in the bronze turkey and its follow-up in age aspect can be used to determine the diet of the studied birds, as well as to determine the intactness of the intestinal mucosa. Our opinion complements that presented facts (9) for the domestic turkey and (10) for broiler chickens.

Our studies on the enzymatic activity of AF in the small intestine of the bronze turkeys show that it reaches peak levels in the first weeks after hatching in all three segments. These facts correspond to data published by some authors $(11,12)$ on the monitoring of $\mathrm{AF}$ activity in the small intestine in broiler chickens in age aspect.

According to our data, the activity of AF in the duodenum, jejunum and ileum in the bronze turkey increases in the first weeks after hatching, and gradually by day thirty-five the activity of the enzyme decreases and remains constant until day two hundred and forty in the three segments of the small intestine. It should be noted that AF activity increases most significantly in the duodenum from the first to the fourteenth day, less in the jejunum and least in the ileum. These data complement that, has been known previously about this isoenzyme in broilers. (6)

\section{CONCLUSIONS}

The enzyme histochemical study of the small intestine in the bronze turkey in the age aspect is highly informative. The obtained data can be used as a morphological basis for monitoring the physiological status of the intestinal mucosa, for determining the appropriate diet of the studied birds and for the diagnosis of specific intestinal diseases, including parasitosis. 


\section{REFERENCES}

1. Ramasamy, S., Nguyen, D. D., Eston, M. A., Alam, S. N., Moss, A. K. and Ebrahimi, F., Intestinal alkaline phosphatase has beneficial effects in mouse models of chronic colitis. Inflamm. Bowel Disease, 17: 532-542, 2011.

2. Fawley, J. and Gourlay, D. M., Intestinal alkaline phosphatase:a summary of its role in clinical disease. Journal of Surgical Research, 202: 225-234, 2016.

3. Lee, C., Chun, J., Hwang, S. W., Kang, S. J., Im, J. P. and Kim, J. S., The effect of intestinal alkaline phosphatase on intestinalepithelial cells, macrophages and chronic colitis in mice. Life Sciences, 100: $118-124,2014$

4. Belabbas, H., Melizi, M., Benkhaled, A. and Adili, N., Post Hatch Development of Alkaline Phosphatase Activity in the Broiler Small Intestine. International Journal of Poultry Science, 14: 203-206. 2015

5. Uni, Z., Functional development of the small intestine in domestic birds: cellular and molecular aspects. Poultry and Avian Biology Reviews, 10: 167-179, 1999

6. Bilski, J., Mazur-Bialy, A., Wojcik, D., Zahradnik-Bilska, J., Brzozowski, B., Magierowski, M., Mach, T., Magierowska, $\mathrm{K}$. and Brzozowski, T., The Role of Intestinal Alkaline Phosphatase in Inflammatory Disorders of Gastrointestinal Tract. Mediators of Inflammation https://doi.org/10.1155/2017/9074601, 2017.

7. Kogut, M. H. and Powell, K. C., Preliminary findings of alterations in serum alkaline phosphatase activity in chickens during coccidial infections. Journal of Comparative Pathology, 108: 113-119, 1993.

8. Sabatakou, O., Paraskevakou, E., TseleniBalafouta, S. and Patsourisp, E., Histochemical study of alkaline phosphatase activity in the chicken
YOVCHEV D., et al. intestine. Bulgarian Journal of Veterinary Medicine, 10, 83-93, 2007.

9. Fasina, Y. O., Garlich, J. D., Classen, H. L., Ferket, P. R., Havonstein, G. B., Grimes, J. L., Qureshi, M. A. and Christensent, V. L., Response of Turkey Poults to Soybean Lectin Levels Typically Encountered in Commercial Diets. 1. Effect on Growth and Nutrition Digestibility. Poultry Science, 83: 1559-1571, 2004

10. Saki, A., Abbasinezhad, M., Ghazi, S., Tabatabai, M., Ahmadi, A. and Zabolil K., Intestinal characteristics, alkaline phosphatase and broilers performance in response to extracted and mechanical soybean meal replaced by fish meal. Agricultural Science and Technology, 14: 105-114, 2012.

11. Yoshimura, Y., Nagano, K. K., Subedi, K. and Kaiya, H., Identification of immunoreactive ghrelin and its mRNAin the oviduct of laying Japanese quail, Coturnix japonica. The Journal of Poultry Science, 42: 291-300, 2005.

12. Yoshimura, Y., Tsuyuki, C., Subedi, K., Kaiya, H., Sugino, T. and Naoki, I., Identification of ghrelin in fertilized eggs ofchicken. The Journal of Poultry Science, 46: 257-259, 2009.

13. Wu, Y., Shao, Y., Song, B., Zhen, W., Wang, Z., Guo, Y., Shahid, M., Nie, W., Yamauchi, K., Kamisoyama, H. and Isshiki, Y., Effects of fasting and refeeding on structures on the intestinal villi and epithelial cells in White leghorn hens. British Poultry Science, 37: 909 - 921, 1996.

14. Pearse, A., Histochemistry theoretical and applied. 2nd ed., J. \& Churchill LTD, London, p. 25 - 261, p. 838, 1962

15. Dimitrov, R., Morphofunctional and imaging features of the male accessories glands and pelvic part of the urethra in the tomcat. $\mathrm{PhD}$ Thesis, Trakia University, Stara Zagora, Bulgaria, 2009 